\title{
CIENCIA: \\ UNIDAD EN \\ LA VARIEDAD
}

\section{Ramón LATORRE* y María Elena MORENO***}

\section{RESUMEN}

Sostenemos en este artículo que la estética en la ciencia es guiada por un afán de encontrar unidad en la variedad. En otras palabras, es unir a través de una teoría común fenómenos aparentemente disímiles. Por otra parte, y de acuerdo a Popper, creemos que el proceso de creación científica está más guiado por la intuición y el "amor" hacia el objeto estudiado que por una lógica precisa. Es en este sentido que la ciencia es la hermana natural de las humanidades.

Palabras claves: Filosofía natural, Renacimiento, lógica e intuición, belleza en el acto creativo.

\section{ABSTRACT}

We sustain that aesthetics in science is governed by finding unity in variety. In other words, a successful theory in science is the one able to give a common explanation to apparently dissimilar phenomena. Following Popper, we think that scientific process is guided more by intuition and "love" for the object under study than by a precise logic. In this regard, the scientific enterprise is the natural sister of the humanities.

Keywords: Natural philosophy, Renaissance, logic and intuition, beauty in the creative act.

Recibido: 05.03.2006. Aceptado: 20.05.2006.

* Premio Nacional en Ciencias Naturales (2002). Profesor y director del Laboratorio de Biofísica del Centro de Estudios Científicos, Valdivia. E-mail: rlatorre@cecs.cl.

** Socióloga. Estudiante del Doctorado en Lingüística y Humanidades, Universidad Austral de Chile, Valdivia. E-mail: memoreno@uach.cl. 


\section{CIENCIA Y HUMANIDADES}

$A R C A N A$

NATUR

Detexta

s.s

Axtokso van LrEמאTEIIDEK.

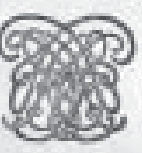

reciua extakgatai

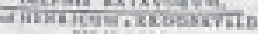

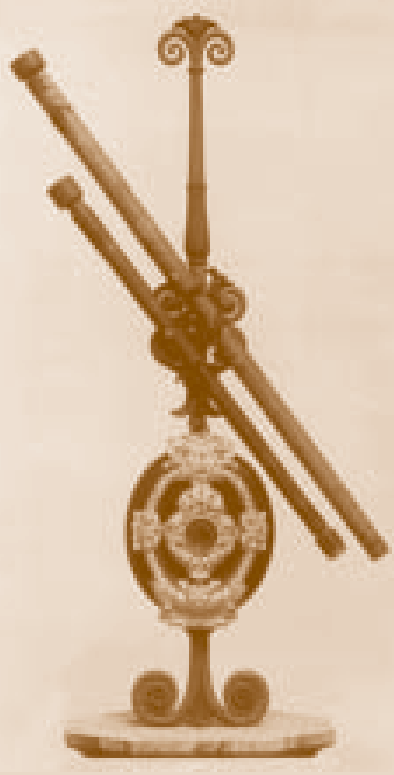

Telescopio de Galileo
$\mathrm{D}$ E ACUERDO a la doctrina cristiana, Dios nos dio dos libros en los cuales sus acciones estaban escritas. Uno de estos libros es la Biblia y el otro es el Libro de la Naturaleza, leyendo este último deberíamos poder adquirir el conocimiento necesario para entender los trabajos de Dios, hayamos o no leído la Biblia. Koestler (1959) nos recuerda que el término "ciencia" reemplazó a su antigua denominación "filosofía natural" que contenía asociaciones ricas y universales en significado. Tanto Kepler (15611630), en su libro La armonía del mundo, como Galileo (1564-1642), en el M ensajero de las estrellas, se refieren a la ciencia como filosofía natural porque estaban leyendo el Libro de la Naturaleza. Esta nueva filosofía produjo una revolución destinada a cambiar la faz del planeta y por primera vez el científico se vale de instrumentos para entender la naturaleza. Galileo recurre al telescopio para espiar el universo, desentrañar sus misterios y describirlos como nadie lo había hecho antes. Hooke (1635-1703) y Leewenhook (1632-1723) enfocan sus microscopios, herederos naturales de los anteojos, a lo más pequeño y revelando desde la maravillosa diversidad de los copos de nieve hasta la existencia de vida en las levaduras, descubren nuevos universos en lo invisible. El estudio de la naturaleza como lo entendemos hoy aparece sólo a partir de la época del Renacimiento, y no antes.

Así como la hermandad pitagórica puso a la ciencia junto a la música y la religión, la ciencia como la entendieron los renacentistas no era sino otra rama de la filosofía: la filosofía de la naturaleza. Koestler (1959) mira esta revolución como una que "en su búsqueda cósmica derriba las murallas del mundo medieval, cambia las jerarquías y los valores morales y transforma el paisaje europeo tan completamente como si una nueva especie hubiera aparecido en nuestro planeta".

Esta "mutación" de la mente de los europeos en el siglo diecisiete introducida por el Renacimiento es un claro ejemplo del impacto de las ciencias en las humanidades y nos ilustra el gran error que se comete cuando se erigen barreras académicas y sociales entre estas dos actividades que ennoblecen a los seres humanos. Y "humano" es precisamente la palabra correcta cuando nos damos cuenta que todos los sistemas cosmológicos, desde los pitagóricos a Copérnico, reflejan prejuicios inconscientes y las posiciones filosóficas o políticas de sus autores. Desde la física a la fisiología, no hay rama de la ciencia que no esté influenciada por algún tipo de metafísica.

La historia de las teorías cósmicas puede sin exagerar ser considerada la historia de obsesiones colectivas y esquizofrenias controladas y la manera en que se llegó a los mas importantes descubrimientos nos recuerda más bien la actuación de un sonámbulo que la de un cerebro electrónico (Koestler, 1959). 

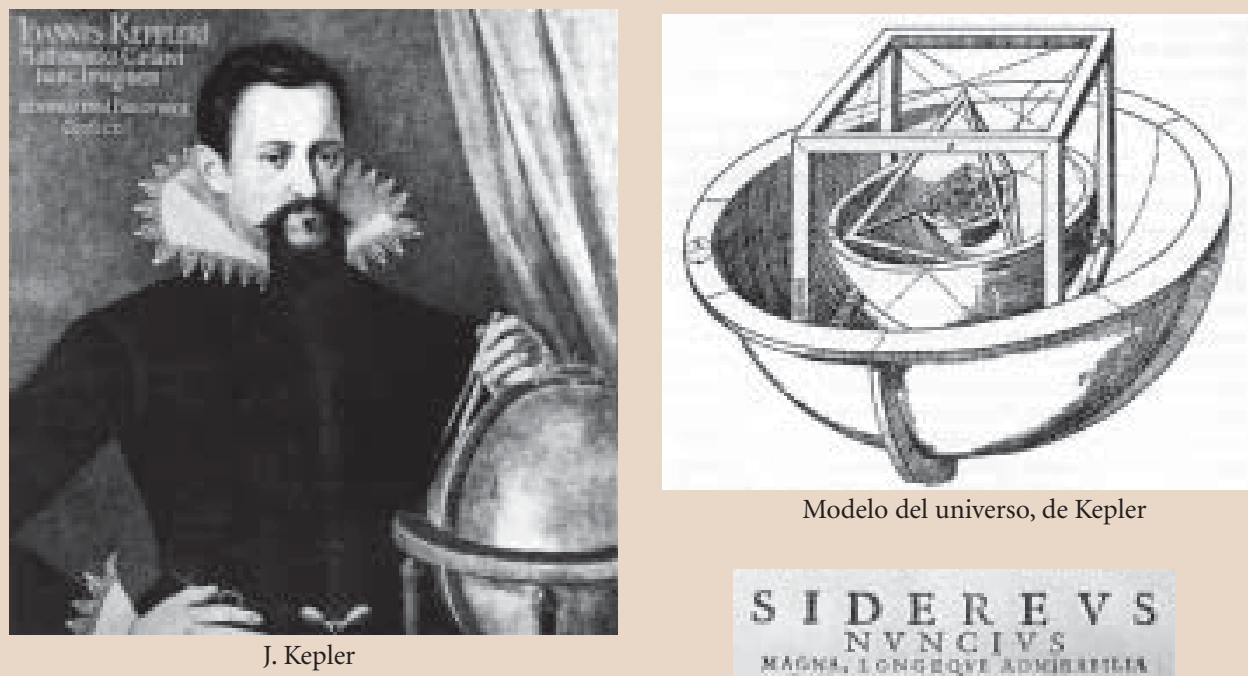

Modelo del universo, de Kepler

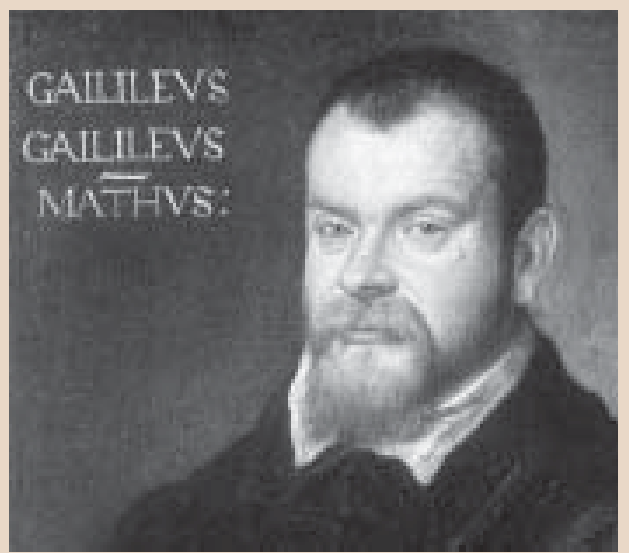

Galileo
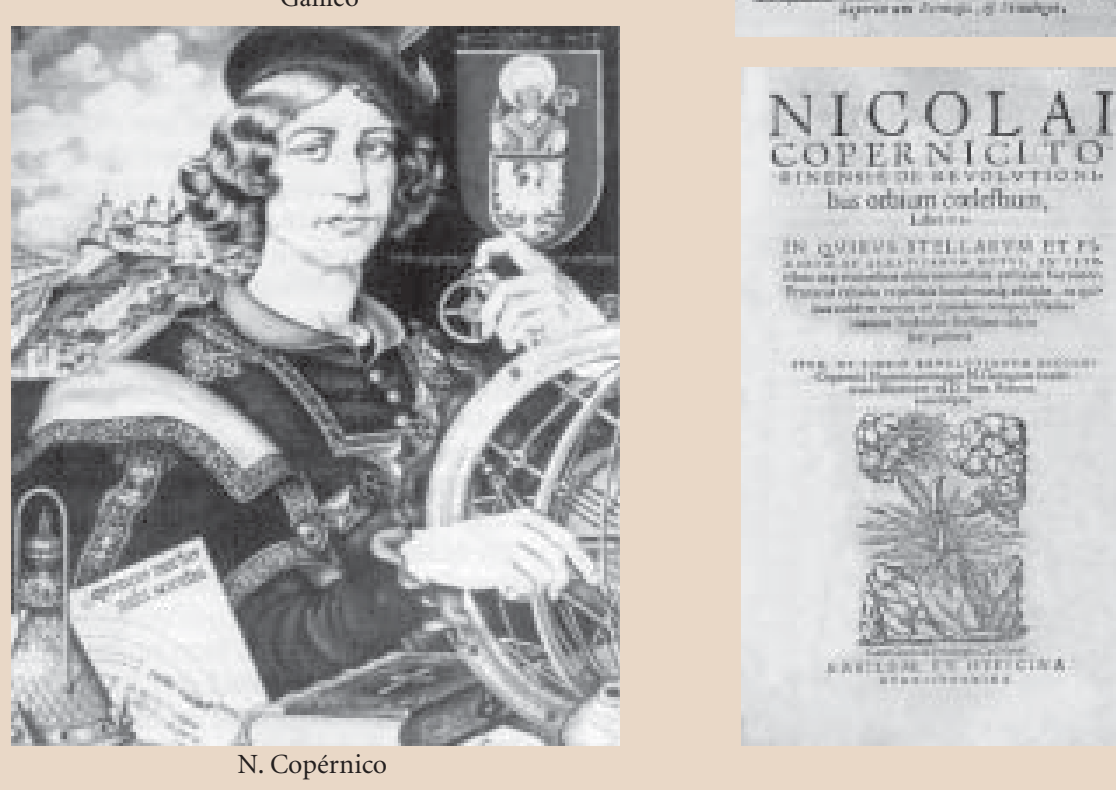

S I D E R E V S

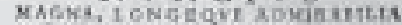

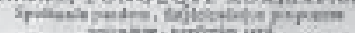

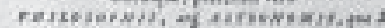
GALILEO GAIILEO FATEITIO FLORENTINO

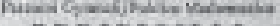
PDR S ICILLI

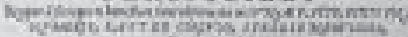

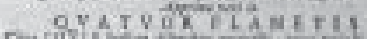

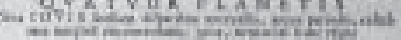
MEDICEA SIDER A NVhCVPANDOS DECAEYI (6)

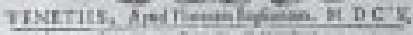

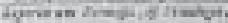



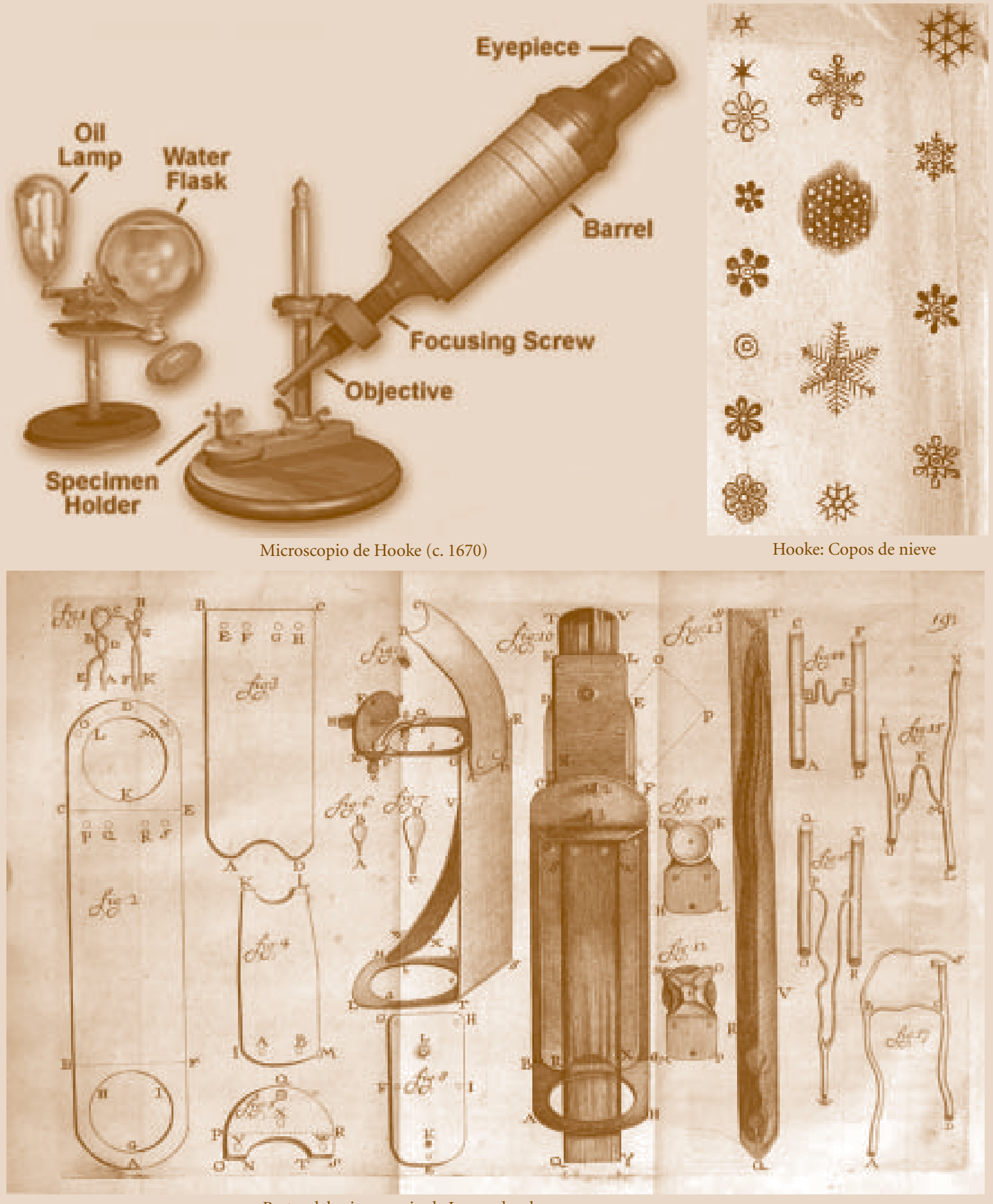

Partes del microscopio de Leewenhook 
Pierde entonces la ciencia ese barniz racional con que se la tiñe usualmente y vemos que está constantemente influenciada por el medio cultural en el cual se desenvuelve.

Sostenemos que las humanidades y la ciencia en nuestra civilización occidental, esa que nace en el mediterráneo, son hermanas siamesas quizá con diferentes cerebros, pero con un solo corazón. Tan unidas están las ciencias de las otras expresiones del intelecto que cuando una se detiene se inmovilizan todas. No hay puente que una el milagro griego con el surgimiento del Renacimiento. En este oscuro periodo lleno de santos y cruzadas se pierde el deseo de leer el Libro dela Naturaleza y se denigra toda manifestación cultural. El tercer volumen de las Instituciones divinas de San Lantacio se titula "Acerca de la falsa sabiduría de los filósofos" y niega la existencia de las antípodas con argumentos tan cándidos como que la gente no podría caminar con los pies sobre la cabeza o que la lluvia no puede caer hacia arriba. San Jerónimo, el traductor de la Vulgata, la versión latina de las Sagradas Escrituras, realiza una batalla de toda la vida en contra de la tentación de leer los clásicos paganos: "Señor, te niego al poseer libros llenos de palabras o si de nuevo llego a leerlos".

Refiriéndose a la literatura clásica Einstein (1982) nos dice:

Lo que sí nos queda claro es que sólo existen unas pocas mentes iluminadas en un siglo y lo que se preserva de su trabajo es uno de los patrimonios más preciosos de la humanidad. Les debemos a unos pocos escritores que nos legaron sus escritos, el hecho que los hombres de la Edad Media hayan podido liberarse lentamente de la superstición y de la ignorancia que oscureció la vida de los hombres y mujeres por más de medio milenio.

Si bien el puente cultural entre la gran edad de Grecia y el Renacimiento se quiebra después de la caída del imperio romano, esos escritos de los que nos habla Einstein son las balsas que permitieron el contacto de estas dos orillas separadas por el religioso río de la Edad Media. El Renacimiento no sólo trae el despertar de las artes en todas sus expresiones, es en el Renacimiento donde aparece la ciencia como la conocemos hoy en día y en donde se vuelve a leer el Libro dela Naturaleza que había sido dejado en el desván por el inmenso y poderoso brazo de Aristóteles.

Teorizar, generalizar y establecer un marco conceptual en un campo de trabajo determinado es considerado por los científicos como parte integral de su trabajo. Sin embargo, muchos epistemólogos consideran que teorizar y la formación de conceptos a la manera de Aristóteles queda dentro del dominio de la filosofía. El primero que marcó esa diferencia entre la filosofía y la ciencia como la conocemos hoy en día fue Galileo Galilei. Con él se inicia la ciencia moderna, siendo el primer investigador del que tenemos

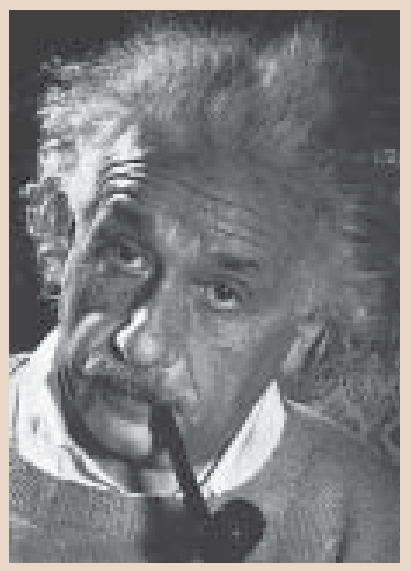

A. Einstein 


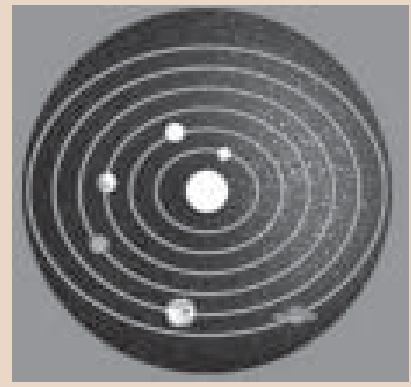

El universo de Kepler

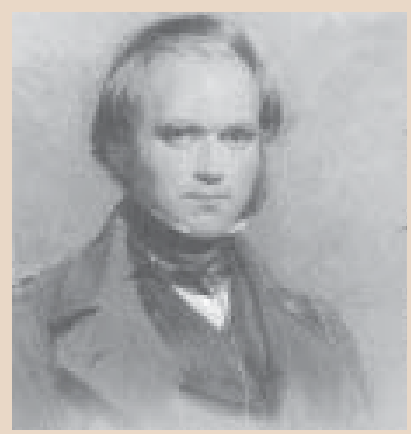

Ch. Darwin noticias históricas. En una sola cita podemos apreciar cómo este gigante intelectual puso patas para arriba el universo aristotélico. Esta cita la encontramos en la Carta a la Gran Duquesa Cristina de Lorena:

Mantengo que el Sol está localizado en el centro de las revoluciones de las órbitas celestiales y que no cambia de lugar y que la Tierra gira sobre sí misma y se mueve alrededor de él. Más aún (...) yo confirmo mis conclusiones no únicamente refutando los argumentos de Aristóteles y Tolomeo sino que apoyándolas en descubrimientos astronómicos(...)" (Reproducción de las cartas de Galileo, 1986).

Muy a menudo escuchamos que la separación entre la ciencia y las humanidades es una consecuencia de la incapacidad de los científicos de apreciar el "elemento humano" cuando realizan sus investigaciones. Sin embargo, no creemos que podamos hacer recaer toda la responsabilidad en los hombros de los científicos. Uno de los más grandes biólogos evolucionistas del siglo pasado Ernst Myer (Myers, 1997) comenta al respecto:

Considerando que conocimientos rudimentarios de biología de la evolución, de las ciencias del comportamiento, del desarrollo humano y de antropología física deberían ser indispensables en la mayor parte de los trabajos que desarrollan las humanidades, es sorprendente que la gran mayoría de los humanistas carecen de esos conocimientos y despliegan una incréble ignorancia de ellos en sus escritos. Se escucha a menudo que esto es debido a la "falta de habilidad en las matemáticas" y, sin embargo, esas áreas de la biología que acabo de mencionar y que deberían ser parte del bagaje cultural de un humanista prácticamente no tienen matemáticas. No hay una sola ecuación en el Origen de las especies de Darwin o en mi libro El crecimiento del pensamiento biológico. El conocimiento de la biología humana debería ser un componente necesario e indispensable de los estudios en humanidades. La psicología por ejemplo se considera ahora una rama de la biología y, sin embargo, uno se pregunta: ¿Es posible escribir algo en el campo de las humanidades ya sea en historia o literatura sin tener un entendimiento considerable del comportamiento humano?

Esta ignorancia de los hallazgos que ha hecho la biología en los tres últimos siglos es particularmente dañina, los humanistas se ven confrontados con problemas políticos como la sobrepoblación del planeta, el esparcimiento de las enfermedades infecciosas, el agotamiento de los recursos no renovables, la proliferación del comportamiento criminal o las fallas de nuestro sistema educacional. Ninguno de estos problemas se puede enfrentar de una manera satisfactoria sin tomar en cuenta los hallazgos de las ciencias y en particular aquéllos de la biología. 


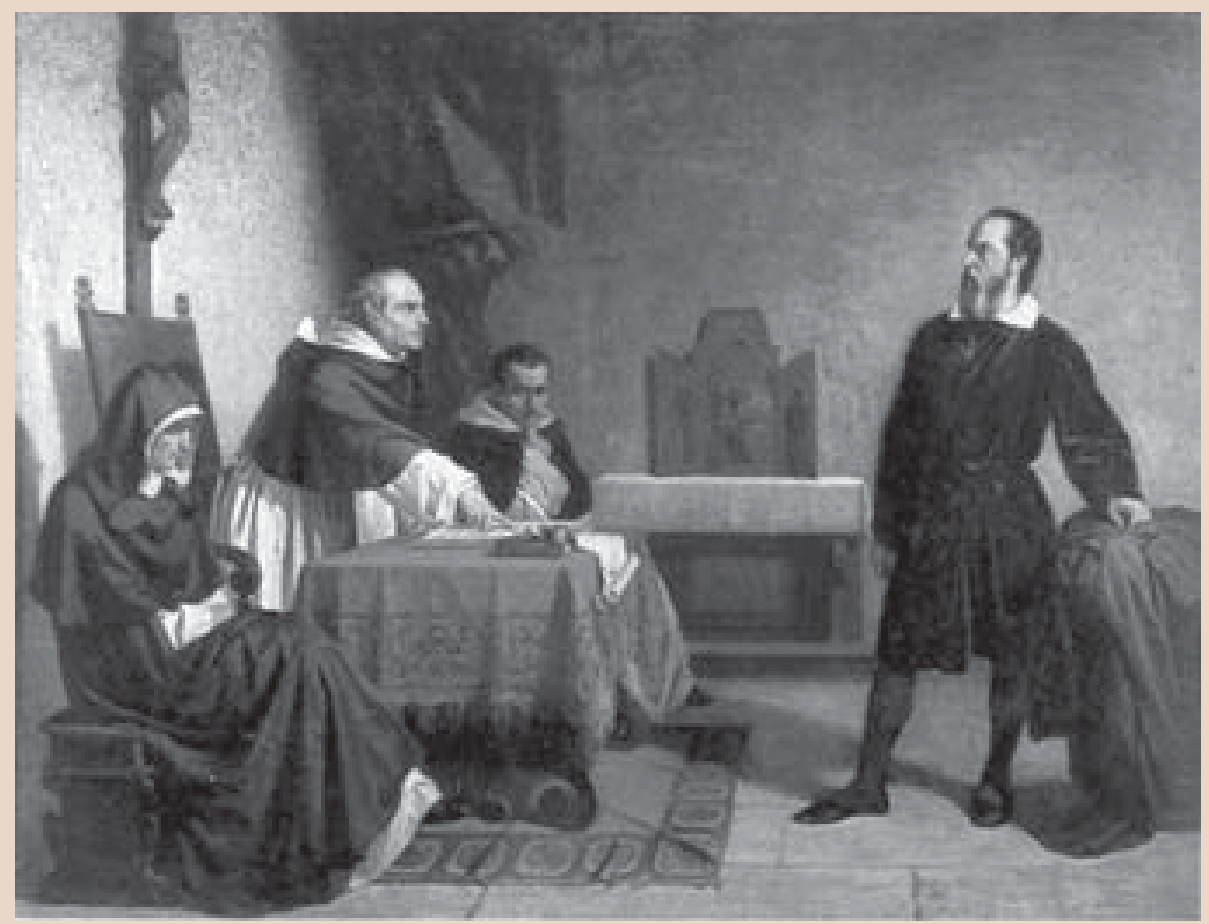

Galileo enfrentando a la Inquisición, por el pintor Cristiano Banti.

\section{CIENCIA, ARTE Y BELLEZA}

¿Sabe usted qué es lo que hace a la obra de arte y qué es lo que hace a la obra de la naturaleza? ¿Sabe usted en qué consiste la diferencia? Porque, al fin y al cabo, la flor del narciso es tan bella como una obra de arte... y lo que la distingue no puede ser la belleza. ¿Sabe usted qué es lo que las distingue? La obra de arte es siempre única.

Estas son palabras de Oscar Wilde, recuperadas a través de los recuerdos de André Gide (1999) en un librito muy bello acerca de este maestro del discurso. Unica es la increíble capacidad del hombre de poner juntas dos cosas que aparentemente son totalmente disímiles: Newton se dio cuenta que la manzana que cae y la luna que no cae están representando el mismo fenómeno: el fenómeno de la gravitación.

Así como la física pone su ojo escudriñador en partículas esquizofrénicas como el electrón, quien en su doble personalidad puede ser una onda o una partícula, la biología investiga desde la conducta de las macromoléculas que contienen toda la información que define a los seres humanos hasta el com-

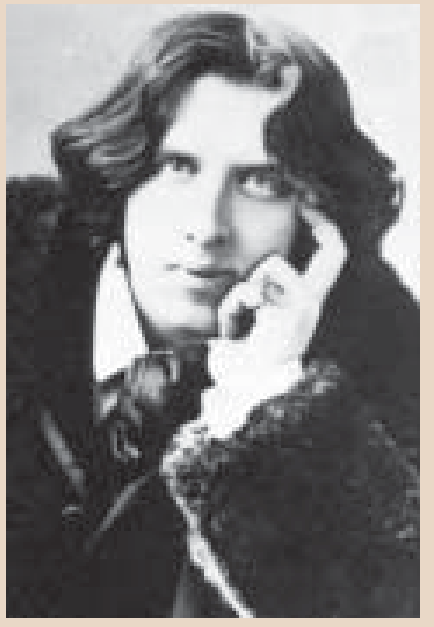

O. Wilde 


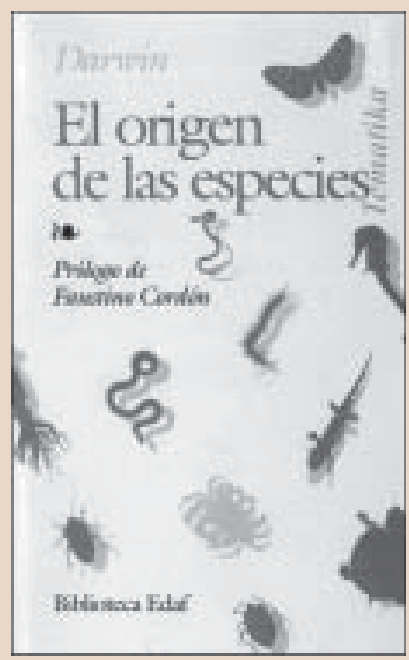

portamiento de los millones de neuronas que componen nuestro cerebro. En este proceso de averiguaciones no tienen cabida el autoritarismo, los dogmas, la deshonestidad o la falta de independencia en el pensamiento.

La ciencia que perdura es la que crea un nuevo paradigma y rompe de manera revolucionaria con los arquetipos anteriores (Kuhn, 1990), lo que implica un acto creativo y es por eso que el científico así como el poeta no puede estudiar una bacteria o manejar una ecuación sin involucrarse intelectual y emocionalmente. En el acto creativo no hay, de acuerdo a Popper (2002), un método lógico que nos permita tener nuevas ideas o, dicho de otra manera, todo acto creativo contiene un elemento irracional. Es más, es la intuición la que nos lleva a una nueva y original manera de mirar los problemas. No hay un camino lógico que nos lleve a encontrar las leyes que rigen el universo y de una manera poética Einstein nos indica que ellas sólo pueden alcanzarse mediante la intuición basada en algo así como un amor intelectual por el objeto con el cual estamos experimentando.

Bronowski (1977), un hombre que exploró la poesía, el teatro, la física y las matemáticas en su libro A sense of future, nos habla con exquisita sensibilidad acerca del quehacer científico.

Un hombre crea, ya sea un artista o un científico, cuando encuentra unidad en la variedad que nos ofrece la naturaleza. Lo hace encontrando afinidades entre cosas que parecían ser diferentes, proporcionándole al mismo tiempo un sentido de riqueza y de entendimiento. La mente creativa es una mente que constantemente busca parecidos inesperados.

Darwin con su O rigen delas especies unificó la biología de la misma manera que Newton o Einstein unificaron la física. El éxito de Darwin reside en el hecho que fue capaz de abarcar todo el mundo orgánico dentro de su teoría de la evolución a pesar de la infinita variedad que encontramos en los seres vivos. Diversidad es la esencia de la vida y el logro fundamental de la teoría de Darwin fue darle coherencia intelectual a esta diversidad.

La naturaleza es caos y el momento más excitante en la vida de un investigador es cuando una cantidad de cosas disímiles cristalizan en una unidad única. "Creatividad es entonces la facultad de la mente o el espíritu que nos hace capaces de producir ostensiblemente de la nada algo bello, ordenado o con algún significado", nos dice Peter Medawar (1990) en su libro Thethreat and the glory.

Pensemos en las nubes, la nieve, el hielo, el agua y el vapor, y que todas estas entidades físicas aparentemente tan diferentes no son sino manifestaciones de la misma molécula que toma distintos aspectos, dependiendo de la temperatura del medio. Pero para llegar a esta conclusión alguien tuvo que pensar en la existencia de los átomos, en la capacidad que éstos tenían para formar moléculas y, finalmente, en dar el salto unificador que nos per- 


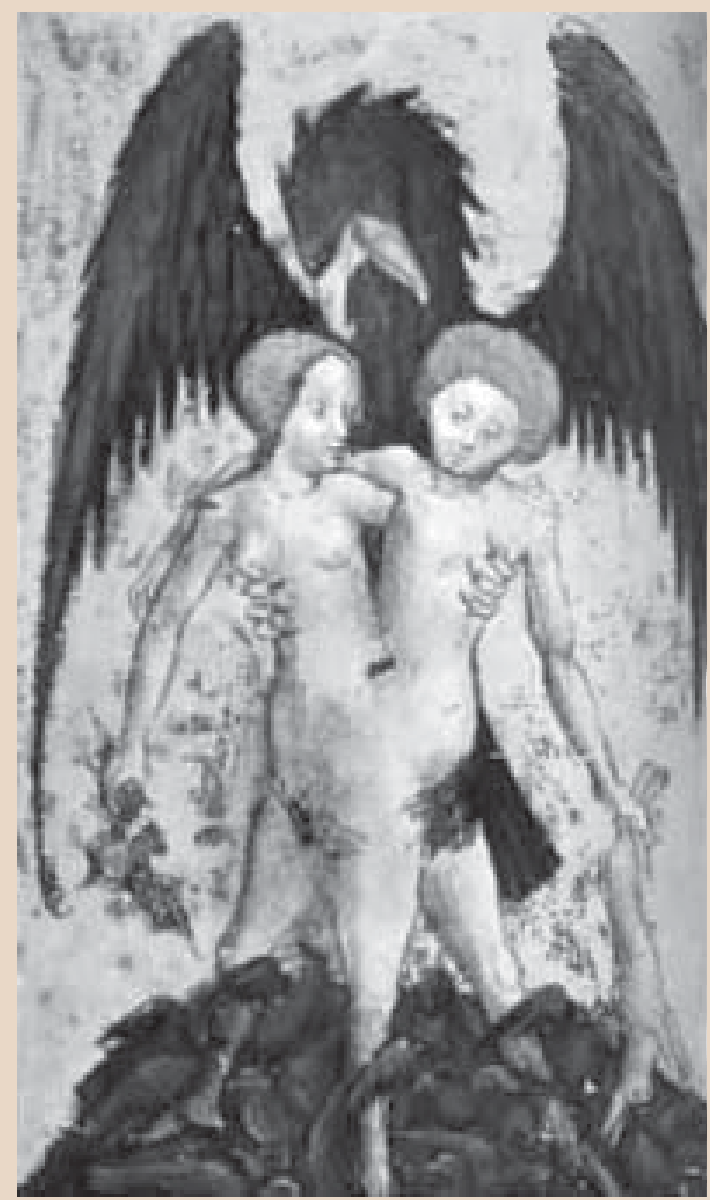

La ciencia y las humanidades, hermanas gemelas.

mite mirar la belleza del copo de nieve y de la gota de agua con la armonía de la unidad.

Cómo da ese salto unificador no es claro. Lo único que sabemos los científicos es que tenemos el mismo problema de la página en blanco que aqueja a los escritores. Pasamos semanas dándonos vueltas y de repente, en la ducha o en un bus, encontramos la solución al problema que no nos dejaba dormir. Esto nos parece un ejemplo característico de cómo la mente gasta un largo tiempo digiriendo el material a su alcance, llegando a la conclusión entonces que un acto de creación no es sino un acto de encontrar el orden adecuado para expresar la complejidad de todo el fenómeno. Y, trivialmente, lo que uno dice, ya sea en las artes o en las ciencias, no existe hasta que no haya sido dicho. 


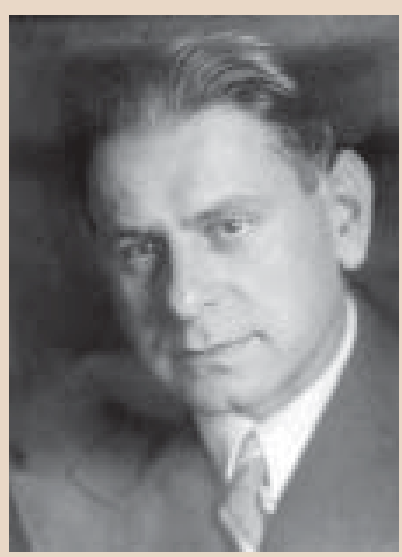

K. Popper

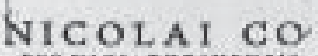

zax Naction

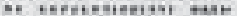
-

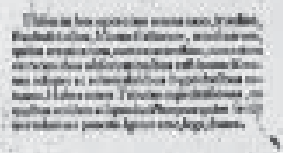

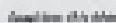
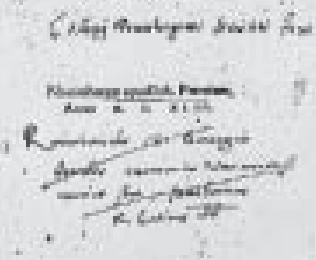

Un científico resuelve problemas. La pregunta es entonces: ¿Cómo lo hace? Es claro que no llega a la solución acumulando hechos e información. La información no es conocimiento. Ninguna nueva verdad se nos aparecerá del interior de un saco lleno de datos. La verdad no está contenida afuera de nosotros, cada descubrimiento, cada incremento en nuestro entendimiento de la naturaleza comienza como un acto preconcebido de la imaginación que nos dice cuál podría ser esa verdad. Esa imaginería, que llamamos hipótesis, cristaliza a través de un proceso que es común a todos los asuntos creativos. Viene de dentro de nosotros y no se puede llegar a ella a través de ninguna aproximación preconcebida de lo que es el descubrimiento. Una hipótesis es como una ley en borrador acerca de lo que el mundo, o alguna parte interesante de él, podría ser. El científico no anda a la caza de hechos sino que prueba hipótesis, nos dice Popper. Los experimentos, entonces, no son sino actos realizados para probar una hipótesis.

Mucho se ha discutido acerca del porqué se escoge una determinada teoría sobre el conjunto de ellas que podrían explicar un determinado conjunto de fenómenos y la palabra "simplicidad" es una que escuchamos muy a menudo. Escogimos una determinada teoría entre todas las que pueden dar cuenta de los hechos que conocemos, porque es la más simple. Este concepto que ha sido discutido en detalle por innumerables investigadores, aunque aparentemente tiene un atractivo estético y/o pragmático, muchas veces no se ajusta a la estrategia que han escogido algunos científicos para decidirse a elegir entre otras teorías posibles. Por ejemplo, la teoría de Copérnico no era la más simple entre las otras que se proponían en su tiempo; demandaba dos rotaciones de la Tierra: una diaria y una anual en lugar de una rotación del Sol. Lo que le pareció "simple" a Copérnico fue algo diferente: un sentimiento estético de unidad. El movimiento de todos los planetas alrededor del Sol fue para él al mismo tiempo simple y hermoso porque expresaba la unidad en el diseño del universo hecho por Dios. Con diferentes matices, eso es lo que nos mueve a los científicos - la naturaleza tiene una unidad y esa unidad hace aparecer sus leyes hermosas en simplicidad.

\section{COLOFON}

La ciencia es un maravilloso modo de obtener conocimiento, pero de ningún modo pensamos que es la única manera de guiar la conducta humana. Hacer una contribución que nos haga entender mejor este mundo en que vivimos es la mayor fuente de satisfacción de un científico. El énfasis se pone a menudo en el descubrimiento, en donde la suerte tiene a veces un papel muy importante. El goce es mayor aún cuando desarrollamos un concepto 
nuevo, un concepto capaz de integrar una cantidad de hechos que parecían inconexos. Este goce pasa, invariablemente para el biólogo, por la rutina de la colección de los datos, el desengaño, la más de las veces de una hipótesis errónea o lo recalcitrantes que son los datos en proporcionarnos las respuestas que andamos buscando. A pesar de todo el sufrimiento, vale la pena emprender esta aventura.

Esto es lo que hace la ciencia, ahondar en incógnitas, develar los misterios que hay en cada objeto que nos rodea: desde el universo hasta la más primitiva de las bacterias, todo está expuesto a la increíble voracidad de la curiosidad humana. ¿Se diferencia en esto de las otras actividades humanas que hacen de la creación una profesión? Creemos que no, ya que todas tratan de poner algún orden en este universo en el que vivimos, que por su inmensa variedad es caótico. Y fue un poeta el que dijo esto. Coleridge en su afán de definir belleza no encontró una mejor que "la unidad en la variedad" (unity in variety).

Lo cierto es que la belleza es una idea, un concepto, tan vasto como preciso. Esta paradoja se observa si pensamos en lo difícil que resulta definirla y describirla, no obstante ante un suceso, evento o fenómeno "sabemos" de inmediato si estamos ante una manifestación de belleza. La belleza conmociona los sentidos, el ser humano siente el placer estético de lo bello, y los científicos hacemos de la belleza nuestra orientación. En otras palabras, uno busca preguntas con sentido estético y únicamente "sabe" que ha encontrado la respuesta cuando cae rendido ante la armonía de un concepto o de una fórmula.

Decíamos que uno "cae rendido" ante la belleza de la fórmula como ocurre a veces ante el encanto de cierta mujer, pero en ciencias la maravilla es que si la fórmula nos produce un placer estético, si el experimento es tan hermoso como un cuadro de Klee, eso significa que la naturaleza funciona así y su estructura responde a este funcionamiento. Por eso puedo afirmar que para nosotros, obreros de laboratorio, la belleza es nuestra brújula.

Quisiéramos, para terminar, citar a Pessoa (2000), porque nadie mejor que él puede resumir lo que hemos dicho:

Siento más pena por los que sueñan lo probable, lo legítimo y lo cercano, que por los que se dejan llevar por el devaneo de lo lejano y lo extraño. Los que sueñan a lo grande o bien son locos o bien creen que sueñan y son felices, o entonces son seres simples para quienes el devaneo es la música del alma, que los acuna sin decirles nada. Para quien sueña lo posible tiene la oportunidad real de la verdadera desilusión.

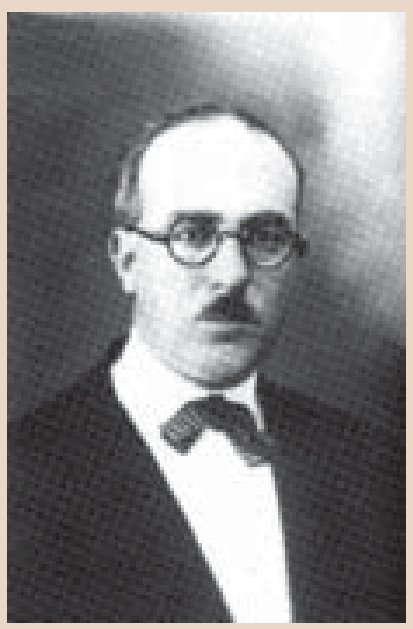

F. Pessoa 


\section{REFERENCIAS}

Bronowski, Jacob. 1977. A Sense of theFuture. Cambridge, M.A. United States of America: The MIT Press.

Darwin, Charles. 2003. On theO rigin of Species. Cambridge, M.A. United States of America: Harvard University Press. A facsimile of the first edition.

Einstein, Albert. 1985. Ideas and O pinions. New York, United States of America: Crown Publishers, Inc.

Galileo Galilei. 1986. Cartas del señor Galileo Galilei, académico linceo, escritas a Benedetto Castelli y a la señora Cristina de Lorena, Gran Duquesa de Toscana. Madrid, España: Alhambra.

Gide, André. 1999. O scar Wilde. Barcelona, España: Lumen, Pocas Palabras.

Kepler, Johanes. 1997. TheH armony of theWorld. Philadelphia, United States of America: Memoirs of the American Philosophical Society, 209.

Koestler, Arthur.1989. The Sleepwalkers. London, England: Arkana, Penguin.

Kuhn, Thomas S. 1990. La estructura de las revoluciones científicas. Buenos Aires, Argentina: Fondo de Cultura Económica.

Mayr, Ernst. 1982. TheGrowth of Biological Thought. Cambridge, Massachusetts, United States of America: The Belknap Press of Harvard University Press.

Mayr, Ernst. 1997. This is Biology. Cambridge, Massachusetts, United States of America: The Belknap Press of Harvard University Press.

Medawar, Peter. 1990. The Threat and the Glory. New York, United States of America: Harper Collins Publishers.

Pessoa, Fernando (como Bernardo Soares). 2000. Libro del desasosiego. Buenos Aires, Argentina: Emecé Editores.

Popper, Karl. 2003. TheLogic of Scientific D iscovery. London, England: Routledge Classics. 